\title{
ELECTROCHEMISTRY OF SOLVATED PROTON IN DIMETHYLSULPHOXIDE-II. KINETICS AND MECHANISM OF THE ELECTROLYTIC EVOLUTION OF HYDROGEN ON IRON*
}

\author{
D. Posadas, J. J. Podestá and A. J. Arvía \\ División Electroquímica, Instituto Superior de Investigaciones, Facultad de \\ Ciencias Exactas, Universidad de La Plata, La Plata, Argentina
}

\begin{abstract}
The kinetics of the electrolytic evolution of hydrogen on iron electrodes using solutions of $\mathrm{HCl}$ in DMSO has been investigated. The electrode reaction was studied within the temperature range from 20 to $45^{\circ} \mathrm{C}$ at various $\mathrm{HCl}$ concentrations, in the presence of an excess of potassium perchlorate.

The mechanism interpreting the electrode reaction comprises as first step the simple solvatedhydrogen-ion discharge as rate-controlling followed probably by a hydrogen adatom combination process. The theoretical parameters derived from this mechanism coincide with the results obtained from steady as well as from non-steady measurements.
\end{abstract}

Résumé- On a étudié la cinétique de la formation électrochimique d'hydrogène avec des électrodes de fer et des solutions d'HCl dans le solvant DMSO. La réaction a été étudiée à des températures de $20 \mathrm{a} 45^{\circ} \mathrm{C}$, a différentes concentrations d' $\mathrm{HCl}$ et en présence d'un excès de perchlorate de potassium.

Les résultats furent interprétés moyennant un schéma ou la première réaction est la décharge simple d'un ion d'hydrogène solvaté, ce qui constitue l'étape régulatrice. La deuxième réaction est probablement la combination des atomes d'hydrogène adsorbée sur l'électrode de fer. II y a une bonne concordance entre les paramètres cinétiques théoriques et les résultats expérimentales.

Zusammenfassung-Es wurde die Kinetik der Wasserstoffabscheidung an einer Eisenelektrode mittels HCl-Lösungen in DMSO untersucht. Die Reaktion der Elektrode wurde über einem Temperaturbereich von 20 bis $45^{\circ} \mathrm{C}$ bei verschiedenen HCl-Konzentrierungen, und einem Ueberschuss von Kaliumperchlorat verfolgt.

Der Mechanismus zur Deutung der Elektrodenreaktion umfasst als erste Stufe die einfache Entladung des solvatierten Wasserstoffs als geschwindigkeitsbest i mmende Stufe und weiter wahrscheinliche eine Kombination von Adsorbiertenwasserstoffatomen. Die von diesem Mechanismus abgeleiteten theoretischen Parameter stimmen mit den Ergebnissen von stationären sowie von nicht-stationären Messungen überein.

\section{INTRODUCTION}

THE HYDROGEN-EVOLUTION reaction employing solutions containing hydrogen ions in organic solvents has already been studied on platinum electrodes. ${ }^{1.2}$ This was possible particularly with solutions of hydrogen chloride in DMSO, since the electrolyte is dissociated to a large extent in the solvent ${ }^{3.4}$ and the solvated hydrogen ion exhibits properties of a simple singly charged species.

To extend the study of the hydrogen-evolution reaction to other solid electrodes, particularly to those where corrosion takes place, is of special interest as far as the kinetics of corrosion processes is concerned. For this reason the present paper refers to the cathodic behaviour of an iron electrode in hydrogen chloride dissolved in DMSO.

\section{EXPERIMENTAL TECHNIQUE}

The electrolysis cells were similar to those described in earlier publications. ${ }^{5}$ They consisted essentially of a Pyrex container with three sections to lodge the working clcetrode, the reference electrode and the counter-electrode.

The working electrodes were made of spectroscopic iron wires of $0.5-\mathrm{mm}$ diameter

* Manuscript received 19 May 1969. 
provided by Johnson, Matthey and Co., with the following impurity limits: Si, $3 \mathrm{ppm} ; \mathrm{Mg}, 2 \mathrm{ppm}$; $\mathrm{Mn}, 2 \mathrm{ppm}$ and $\mathrm{Cu}$ and $\mathrm{Ag}$, less than $1 \mathrm{ppm}$. The wires were supported by a Teflon rod and the apparent area in contact with the solution was about $0.5 \mathrm{~cm}^{2}$.

In order to obtain a reproducible area, the iron wires were electropolished prior to each experiment. After microscopic observations of iron wires treated with different electropolishing solutions, we employed perchloric acid $10 \%$-butylcellosolve $90 \%$ at $5^{\circ} \mathrm{C}$, the wires being electropolished at $14-15 \mathrm{~V}$ and $1.8 \mathrm{~A}$ for $1 \mathrm{~min}$.

A Radiometer calomel electrode, Type $\mathrm{K}-401$, dipped into an intermediate $\mathrm{HCl} / \mathrm{DMSO}$ solution, was used as reference electrode.

The counter-electrode was a platinum sheet of about $8 \mathrm{~cm}^{2}$ located in the anode compartment, preventing anode impurities from interfering with the cathodic reaction.

Dimethylsulphoxide from Flüka, purified as already described, ${ }^{1.3}$ was used. The amount of water was qualitatively tested with calcium hydride and the impurities by gas chromatography. ${ }^{\circ}$

The hydrogen-chloride solutions were prepared following a procedure described elsewhere. 1.3 Potassium perchlorate from Carlo Erba, previously dried, was employed as supporting electrolyte in some of the experiments.

The electrolyte solutions were saturated either with $\mathrm{H}_{2}$ or $\mathrm{N}_{2}$. These gases were freed from oxygen by passing them through a solution of chromium sulphate and sulphuric acid over amalgamated zinc. ${ }^{7}$ Solutions of $\mathrm{HCl}$, in the presence of potassium perchlorate ( $1 \mathrm{M}$ ), in the concentration range from 0.001 to $0.125 \mathrm{M}$, were employed, and a $0.771 \mathrm{M} \mathrm{HCl}$ solution without the addition of the supporting electrolyte was also tested. With both kinds of solution, experiments were performed within the temperature range from 20 to $45^{\circ} \mathrm{C}$, both under galvanostatic and potentiostatic conditions.

The cathodic overvoltage decay as well as its galvanostatic build-up were recorded with conventional procedure.

\section{Current efficiency}

\section{RESULTS}

The current efficiency was measured by collecting the hydrogen gas produced in the cathodic reaction after the solution had been saturated with hydrogen gas. In the cd range from $1 \times 10^{-3}$ to $2 \times 10^{-3} \mathrm{~A} / \mathrm{cm}^{2}(C=0.02 \mathrm{M})$ it was practically $100 \%$. Thus, the over-all cathodic reaction was

$$
2 \mathrm{H}^{+} \text {(solv) }+2 \mathrm{e}=\mathrm{H}_{2} \text { (g). }
$$

At the highest potentials reached in the cathodic experiments no by-products yielded by cathodic reduction of the solvent were detected, as was to be expected considering the stability of the solvent. ${ }^{\mathrm{s}}$

\section{Current/voltage curves}

When the iron electrode was dipped into HCl-DMSO solutions neither hydrogen-gas evolution nor any appreciable attack of the metal was observed and a stable potential was achieved. The latter was taken as the reference potential to define the cathodic overvoltage. When no current passes, the rest potential of the iron electrode probably lies close to the reversible potential, as deduced from the current/voltage curves. 
The galvanostatic and potentiostatic current/voltage curves were always coincident. These curves were plotted as a usual Tafel line for experiments covering a cathodic overvoltage of about $0.3 \mathrm{~V}$. The characteristic forms of the Tafel lines are seen in Figs. 1 and 2 after correction for the pseudo-ohmic and concentration polarization terms. At cathodic overvoltages larger than $0.05 \mathrm{~V}$, the semilogarithmic plots fit fairly well on a straight line having a slope of about $0.120 \mathrm{~V} /$ decade at $25^{\circ} \mathrm{C}$. At low ed when hydrogen-saturated solutions were used, the line curves towards the rest potential of the iron electrode when no current passes, as the ionization of hydrogen

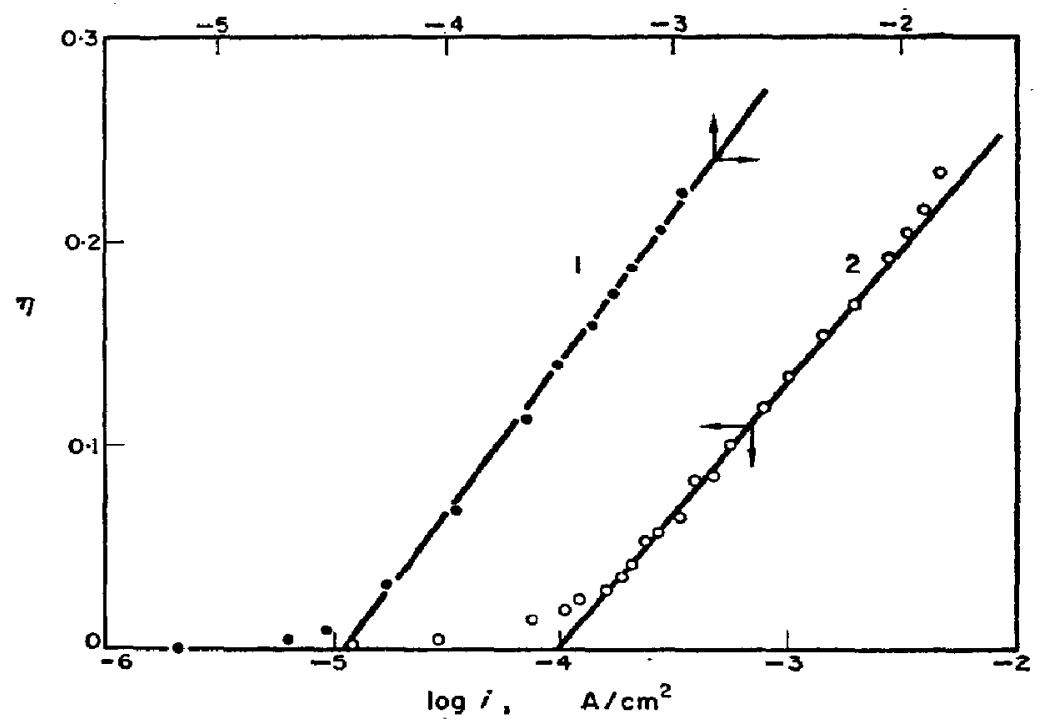

Fig. 1. Tafel plots at $25^{\circ} \mathrm{C}$.

$1,0.025 \mathrm{M} ; 2,0.125 \mathrm{M}$.

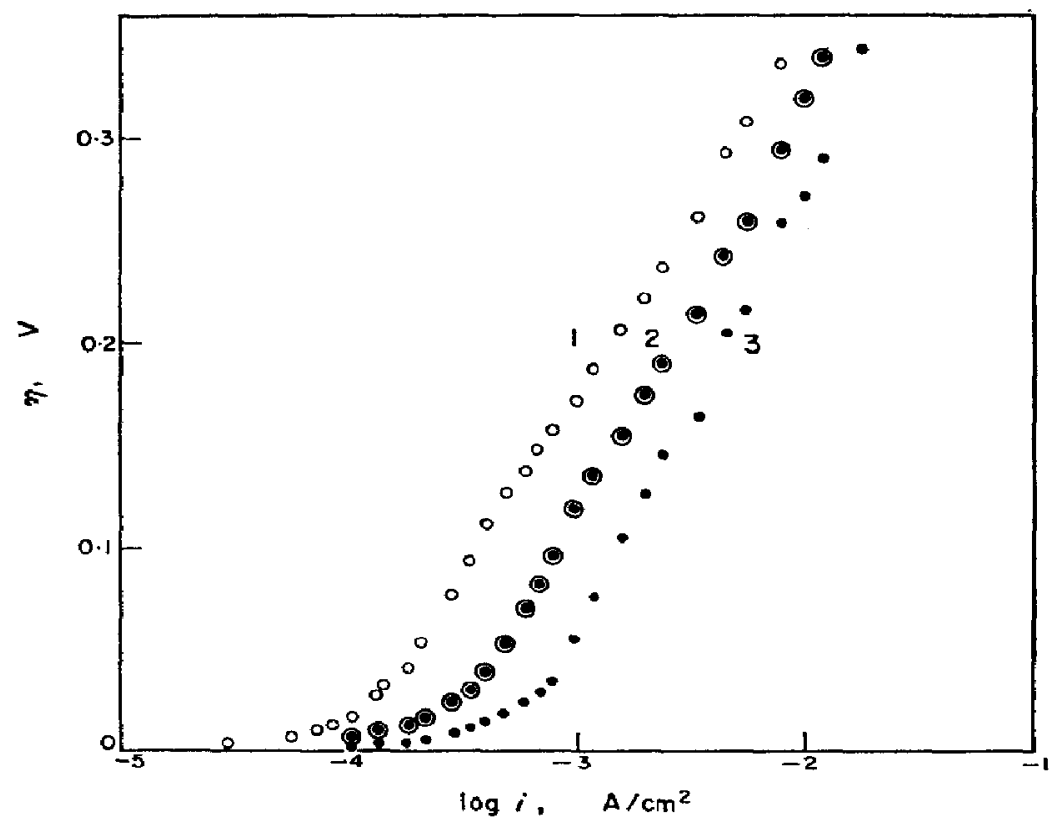

Fig. 2. Effect of temperature on Tafel plots. $0.771 \mathrm{M} ; 1,25^{\circ} ; 2,35^{\circ} ; 3,45^{\circ} \mathrm{C}$. 
becomes appreciable. Therefore current/voltage curves, at the lowest cds, were also plotted as a linear $\eta / i$ function, to evaluate the stoichiometric number, $\nu$. These plots are satisfactory up to overvoltages of about $0.05 \mathrm{~V}$, as shown in Fig. 3 for a set of experiments at different hydrogen-chloride concentrations.

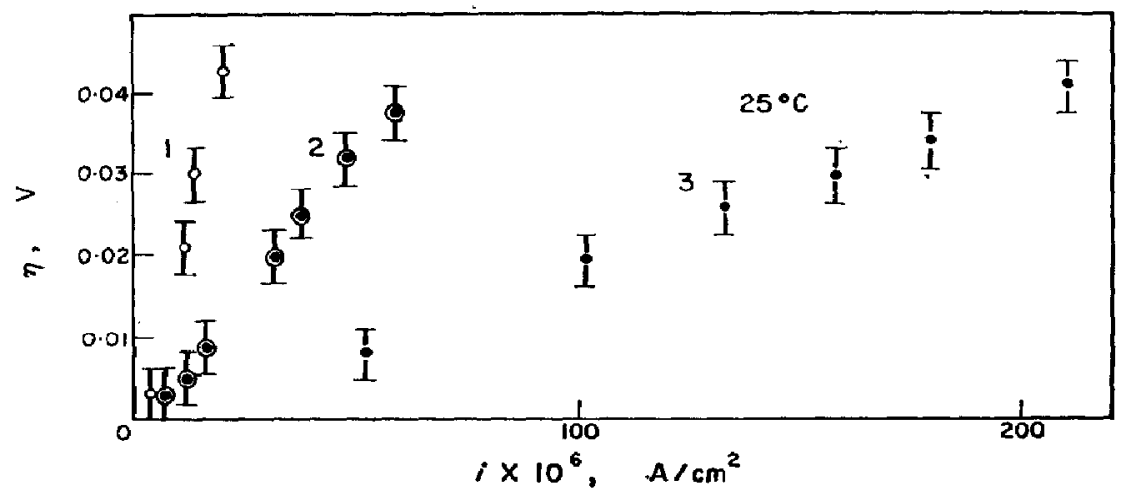

Fig. 3. Linear $\eta / i$ plots at different concentrations.

$1,0.001 \mathrm{M} ; 2,0.005 \mathrm{M} ; 3,0.771 \mathrm{M}$.

The Tafel slope, $b_{\mathrm{T}}$, the apparent cd at the rest potential, $i_{\eta=0}$, and the stoichiometric number, $v$, inferred from current/voltage curves are assembled in Table 1. The average stoichiometric number is about 2.

TABle 1. KINETIC PARAMETERS DERIVED FROM CURRENT/VOLTAGE CURVES

\begin{tabular}{|c|c|c|c|c|c|}
\hline $\begin{array}{c}\text { Conc } \\
\mathbf{M}\end{array}$ & ${ }^{\circ} \mathrm{C}$ & 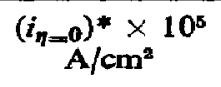 & $b_{\mathrm{x}} \times 10_{\mathrm{V}}^{\mathrm{s}}$ & $\begin{array}{c}\left(i_{\eta=0} / \nu\right) \times 10^{5} \\
\mathrm{~A} / \mathrm{cm}^{2}\end{array}$ & $y$ \\
\hline $\begin{array}{l}0.771 \\
0.125 \dagger \\
0.025 \dagger \\
0.005 \dagger \\
0.001 \dagger\end{array}$ & $\begin{array}{l}25 \cdot 0 \pm 0 \cdot 1 \\
25 \cdot 0 \\
30 \cdot 0 \\
25 \cdot 0 \\
25 \cdot 0\end{array}$ & $\begin{array}{c}12 \cdot 6 \\
9 \cdot 9 \\
3 \cdot 87 \\
3 \cdot 12 \\
(0 \cdot 9)\end{array}$ & $\begin{array}{l}180 \pm 10 \\
130 \\
150 \\
137 \\
(130)\end{array}$ & $\begin{array}{l}6.40 \\
4.93 \\
1.85 \\
1.77 \\
0.51\end{array}$ & $\begin{array}{c}1.96 \\
2.00 \\
2.09 \\
1.76 \\
(1.80)\end{array}$ \\
\hline
\end{tabular}

* The estimated error is about 20 per cent.

† With $1 \mathrm{M} \mathrm{KClO}_{2}$ as supporting electrolyte.

\section{Non-steady measurements}

Semilogarithmic plots of overvoltage decay are shown in Fig. 4. A reasonable straight line can be drawn for the overvoltage range from about 0.250 to $0.05 \mathrm{~V}$. The electrode-potential region where the linear relationship is obtained coincides with the one where a good Tafel line is found in current/voltage measurements. From the $\eta / \log \left(\right.$ time) plots, the decay slope, $b_{\mathrm{d}}$, and the apparent electrode capacitance, $C_{e}$, were evaluated. These results are seen in Table 2 . Decay slopes are potential-dependent, approaching the value $2 \cdot 3(2 R T / F)$ at the highest overvoltages investigated.

From build-up curves, the electrode capacitance at the rest potential was determined. These results are assembled in Table 3 . The electrode capacitance is rather small, about $15 \mu \mathrm{F} / \mathrm{cm}^{2}$, and it is not possible to deduce any potential dependence of it.

\section{DISCUSSION}

The Tafel slope is not enough to establish the mechanism of the electrode reaction. Two important parameters in addition to the Tafel slope and the stoichiometric 


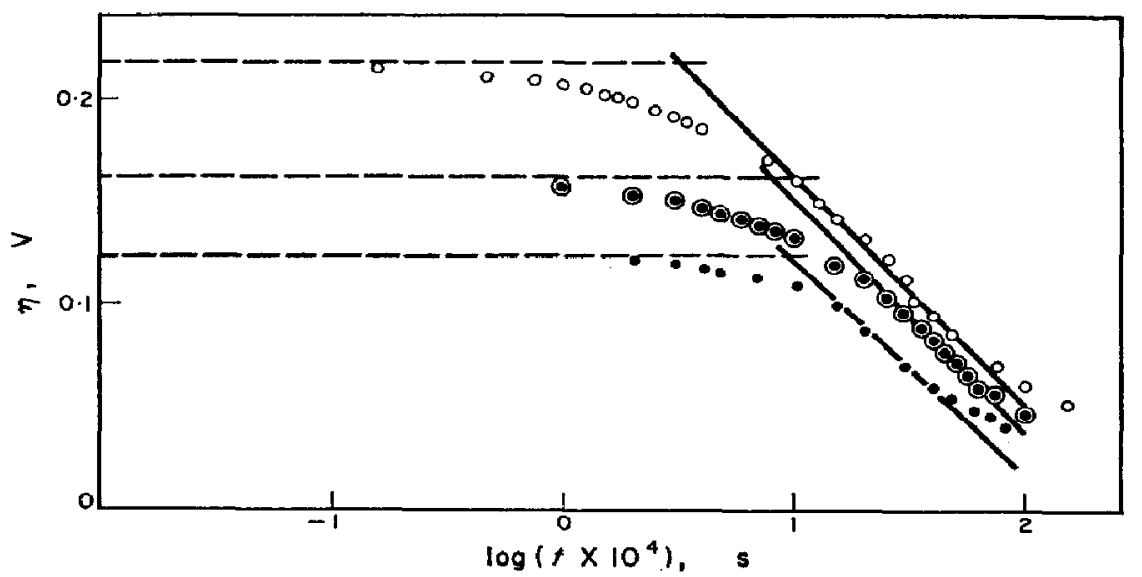

Fio. 4. Semilogarithmic plots of cathodic overvoltage decay at $25^{\circ} \mathrm{C}$. $0.771 \mathrm{M}$.

Table 2. Parameters derived from overvoltage decay curves at $25^{\circ} \mathrm{C}$

\begin{tabular}{cccc}
\hline $\begin{array}{c}\text { Conc } \\
M\end{array}$ & $\begin{array}{c}\eta \times 10^{3} \\
\mathrm{~V}\end{array}$ & $\begin{array}{c}b_{\mathrm{d}} \times 10^{\mathrm{s}} \\
\mathrm{V}\end{array}$ & $\begin{array}{c}C_{\mathrm{e}} \times 10^{\mathrm{s}} \\
\mu \mathrm{F} / \mathrm{cm}^{2}\end{array}$ \\
\hline 0.771 & 217 & 130 & 12 \\
0.771 & 161 & 115 & 19 \\
$0.125^{*}$ & 240 & 120 & 21 \\
$0.125^{*}$ & 198 & 98 & 13 \\
\hline
\end{tabular}

* With $1 \mathrm{M} \mathrm{KClO}_{4}$ as supporting electrolyte.

Table 3. Parameters deduced from galvanostatic butld-up CURVES AT $25^{\circ} \mathrm{C}$

\begin{tabular}{rcc}
\hline $\begin{array}{r}i \times 10^{\circ} \\
\mathrm{A} / \mathrm{cm}^{2}\end{array}$ & $\begin{array}{c}C_{E} \times 10^{8} \\
\mu \mathrm{F} / \mathrm{cm}^{2}\end{array}$ \\
25.0 & $0.001 \mathrm{M}^{*}$ & 8 \\
40.6 & & 11 \\
58.6 & $0.005 \mathrm{M}^{*}$ & 12 \\
77.0 & & 15 \\
141.5 & & 17 \\
236.0 & $0.125 \mathrm{M}^{*}$ & 15 \\
& & 12 \\
1,410 & & 12 \\
2,660 & $0.771 \mathrm{M}^{*}$ & 19 \\
6,000 & & 11 \\
210 & & $9 \cdot 3$ \\
412 & & $9 \cdot 3$ \\
692 & & 8.2 \\
1,124 & & $9 \cdot 0$ \\
2,410 & & \\
\hline
\end{tabular}

* With 1 M KClO^ as supporting electrolyte. 
number are derived by taking into account the concentration dependence of the exchange $c d$ and the temperature effect on the reaction rate.

Figure 5 shows the dependence of the $c d$ at $\eta=0$ on concentration, as obtained by chemical analysis; only experiments run in the presence of the supporting electrolyte are shown, to minimize any influence due to change of the activity coefficient of the

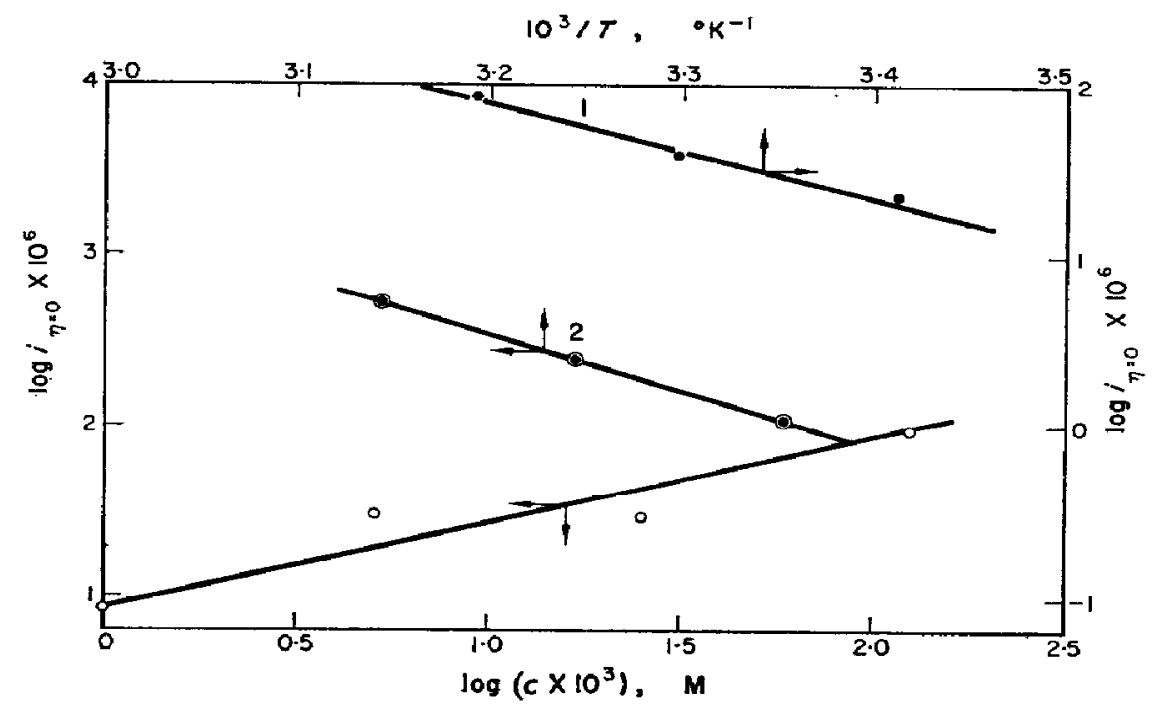

FIG. 5. Temperature and concentration dependences of the apparent $\mathrm{cd}$. $1,0.025 \mathrm{M} ; 2,0.771 \mathrm{M}$.

hydrogen chloride in the solution and to approach a constant ionic distribution at the reaction interface. From the $\log / \log$ plot we get

$$
\left(\frac{\partial \ln i_{\eta=0}}{\partial \ln c}\right)_{\eta=0, \psi_{1}} \approx\left(\frac{\partial \ln i_{0}}{\partial \ln c}\right)_{n=0, \psi_{1}}=\frac{1}{2},
$$

where $i_{0}$ and $\psi_{1}$ are respectively the exchange cd and the electrical potential at the outer plane of the electrical double layer.

The effect of temperature on the cd is obtained either at $\eta=0$ or at different overvoltages, as shown in Fig. 5. As expected, the experimental activation energy derived from the Arrhenius plot is a linear function of the electrode potential, Fig. 6. The $\Delta \mathbf{H}^{\ddagger}$ value, at $\eta=0$, is $15.8 \pm 2.0 \mathrm{Kcal} / \mathrm{mole}$.

The overvoltage decay after current interruption within a rather large range of potential follows a linear $\eta / \log t$ plot. When data are taken at an initial overvoltage larger than about $0 \cdot 150 \mathrm{~V}$, the decay slope is close to $2 \cdot 3 \times 2 R T / F$, coinciding with the slope obtained from steady current/voltage curves. Furthermore the electrode capacitance lies between 10 to $20 \mu \mathrm{F} / \mathrm{cm}^{2}$, and shows no particular trend with the electrode potential. This is an indication that no appreciable contribution of any pseudo-capacitance to the total capacitance exists. Hence there are six kinetic parameters that may be used to obtain the probable reaction mechanism. The first conclusion drawn from them is that the hydrogen-evolution reaction on iron in DMSO-HCl solutions in the potential range investigated is under activation control.

Secondly, the results derived from the non-steady measurement show two interesting points (i) the faradaic process involved in the discharge of the electrical double 


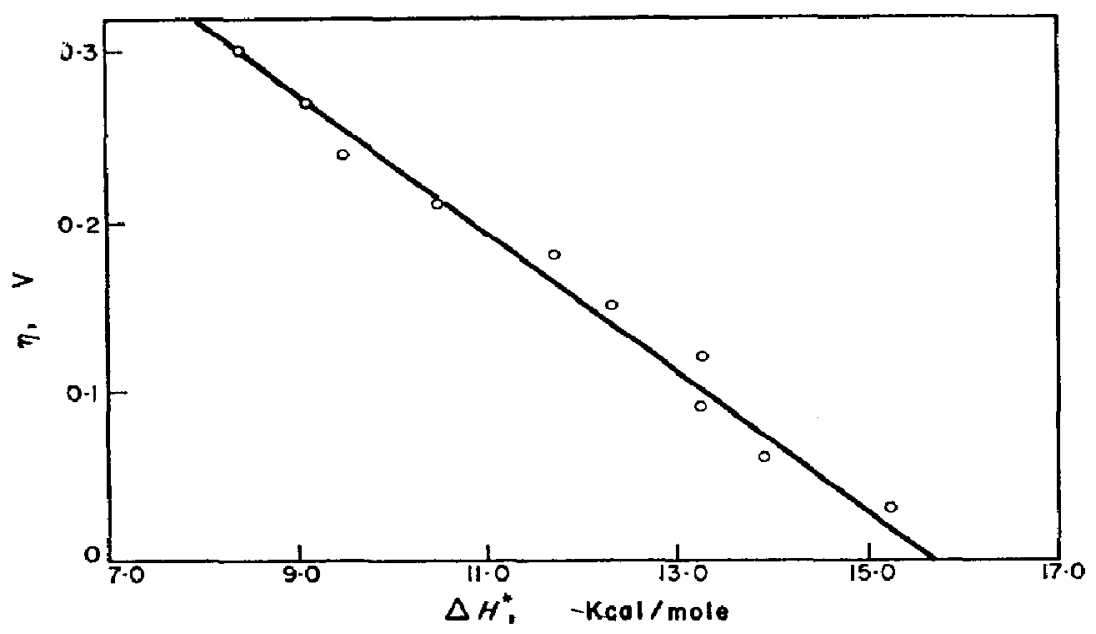

Fig. 6. Dependence of the apparent activation energy on overpotential.

layer is apparently equivalent to that occurring under steady conditions (ii) the features of the electrode capacitance already indicated mean that no appreciable accumulation of reaction intermediates on the electrode surface occurs during the faradaic process. On the basis of (i) and (ii), the Tafel slope and the decay slope should correspond. ${ }^{9}$

The set of kinetic parameters indicates that, in the present circumstances, the mechanism of hydrogen evolution can be postulated in terms of a simple reaction scheme based on a Langmuir adsorption isotherm, involving as rate-controlling step the initial electron-transfer process,

$$
\mathrm{H}^{+} \text {(solv) }+\mathrm{Fe}(\mathrm{e}) \rightleftarrows(\mathrm{H}) \mathrm{Fe}+\text { solv, }
$$

the degree of surface coverage by hydrogen atoms approaching zero. A hydrogen atom on the iron surface may have the following fates (i) it can diffuse into the metal if the latter is still unsaturated (ii) it can react with another, yielding a hydrogen molecule (iii) it can participate in the dissolution reaction yielding back a hydrogen ion, although the probability that this will occur should be very small. However, at large negative potentials and in a quasi-steady state possibility (ii) is the only significant one. Taking into account that the stoichiometric number is 2 , it is likely that the final step yielding molecular hydrogen following the rate-controlling step is an atom plus atom reaction,

$$
(\mathrm{H}) \mathrm{Fe}+(\mathrm{H}) \mathrm{Fe} \rightleftarrows \mathrm{H}_{2}+2 \mathrm{Fe} \text {. }
$$

Assuming that (3) is rate-controlling, the theoretical Tafel line, stoichiometric number, and concentration dependence of the reaction rate for a concentrated solution ${ }^{10}$ agree with those found in the experiments. Therefore, the mechanism of hydrogen evolution on pure iron with solution of $\mathrm{HCl}$ in DMSO is formally comparable to the reaction in aqueous solutions ${ }^{10-13}$ although the apparent $c d$ at $\eta=0$ for the former is about one order of magnitude higher than for the latter.

The apparent activation energy of the reaction is reasonable for the mechanism of reaction already postulated, but it is at present difficult to establish a comparison with data derived for the hydrogen-evolution reaction on iron in other solvents, including water. ${ }^{14}$ 
Acknowledgement-This work was in part supported with financial aid by the Consejo Nacional de Investigaciones Cientificas y Técnicas of Argentina. J. J. P. participated in the project as a part-time researcher of the Chemical Engineering Department. D. P. is grateful for fellowship granted by the C.N.I.C.T. of Argentina.

\section{REFERENCES}

1. C. PAPON and J. JACQ, Bull. Soc. chim. Fr., 13 (1965).

2. J. A. OLABE and A. J. ARviA, Electrochim. Acta 14, 785 (1969).

3. J. A. Bolzán and A. J. Arvía, Electrochim. Acta 15, 39 (1970).

4. J. A. BolzAN and A. J. ARví, Electrochim. Acta 15, 827 (1970).

5. M. C. Gtordano, J. C. BAzÁn and A. J. ARviA, Electrochim. Acta 11, 1553 (1966).

6. T. J. WALlACE and J. J. MaHON, Nature Lond. 201, 817 (1964).

7. D. Gilroy and J. E. O. MAYNE, J. appl. Chem. 12, 382 (1962).

8. J. Courtot-Coupez and M. Le DémézeT, Bull. Soc. chim. Fr., 4744 (1967).

9. E. GILEADI and B. E. CONWAY, in Modern Aspects of Electrochemistry, eds. J. O'M. BockRIs and B. E. Conway, Vol. 3, p. 347. Butterworths, London (1964).

10. B. E. CoNway, Theory and Principles of Electrode Processes. Ronald Press, New York (1965).

11. N. Pentland, J. O'M. Bockris and E. Sheldon, J. electrochem. Soc. 104, 182 (1957).

12. J. O'M. Bockrrs and D. F. A. KoCH, J. phys. Chem. 65, 1941 (1961).

13. E. J. KelLY, J. electrochem. Soc. 112, 124 (1965).

14. B. E. Conway, Electrochemical Data, Chap. X, p. 347. Elsevier, Amsterdam (1952). 